\title{
MODELING AND SIMULATION OF RETRIEVING PROCESS
}

\author{
Shih Y. Chin \\ Department of Mechanical Engineering \\ 400 Av. Tr. São Carlense, University of São Paulo \\ São Carlos, CP: 359 CEP: 13566-590, BRAZIL
}

\author{
José H. C. G. Júnior \\ Department of Mechanical Engineering \\ Federal University of Itajubá \\ Itajubá, M. G., CEP: 37500-903, BRAZIL
}

\begin{abstract}
This paper presents a model of Parts Distribution Center (PDC), developed in Arena ${ }^{\circledR}$ 5.0, which aims at providing information about the total time of the retrieving process as the system is working under unexpected situations. This time is influenced by several variables such as shelves dimensions, routing velocity and mass of the parts. Elaborated solutions are presented to model those variables emphasizing the route, which is considered as the main factor that influences the process time. The results obtained in simulations make understandable the dynamic system and are also capable of supporting managers in decisions such as estimating the required number of employees responsible to order consolidation.
\end{abstract}

\section{INTRODUCTION}

A PDC is responsible for activities from receiving parts provided by suppliers to ordering and delivering consolidation to customers. According to Junior (2000), customers demand exerts high pressure on activities of PDC.

The way of how companies react to those pressures defines performance goals. To remain competitive, companies must reach those goals constantly (Shih et al. 2004a). For instance, the time period from the moment in which a customer requires a product until receives it is named fastness, see Slack et al. (1999). For those reasons it is important for a PDC to be prepared for demand variations.

If the demand were constant and with a few number of items, the experience of managers would be sufficient for taking decisions, but this does not happen in most cases. Even so managers are important in PDC systems related to activities coordination for the well functioning of these systems (Van den Berg 1996, Makris and Giakoumakis 2003).

A retrieving process, according to Hall (1993), is defined as a stage in which items are removed from shelves, but previously orders need to be converted in Collecting Lists (CL), where code and quantity of each item are registered, and ordered in the sequence of retrieving.
The main issue exposed in the literature is related to the cost of this process. Coyle et al. (1996) affirm that the cost of retrieving process is around 50 to $70 \%$ of PDC total cost. Companies should search for minimization of retrieving time because it is similar to reducing cost (Frazelle 1989, Ratliff and Rosenthal 1983).

Several authors searched new methods to realize routing in aisles. Caron et al. (2000) proposed routing in different configurations. Caron et al. (1998) compared different strategies of routing in aisles based on items allocation COI. COI (Cube-per-Order Index) is defined as the space occupied in shelves divided by the demand frequency. In fact, the use of COI increases significantly the performance of retrieving process (Kallyna and Lynn 1976).

Rana (1990) proposed an algorithm for narrow aisles to obtain an estimate of the number of trips for parts collection. Moreover, it was possible to know how were the trolleys route and also the number of collected boxes by trip. Jarvis and McDowell (1991) developed an analytical model to obtain routing values for several allocating polices.

Several routing policies in aisles can be seen in Ratliff and Rosenthal (1983) and Hall (1993). The latter presented, for instance, the results of distances for different aisle widths and routing strategies. Those results were obtained since the number of collecting places had been defined. Moreover, it made comparative analyses among those results to verify which one was the best strategy to be adopted when the number of collecting places was known.

Main papers work with variables such as allocation policy of items in shelves and layout. However, proposals presented in those papers adopt simplifications which provide results different from real systems. For instance, the simulation model proposed by Caron et al. (2000) provides routing values if it was previously estimated the average number of items in each aisle. In practical situations, it is important to evaluate with more accuracy the items positions for better distance estimation. Authors such as Goetschalckx and Ratliff (1988) presented proposals for routing in aisles for a specific shelves position. The routing was obtained connecting collecting places. Nevertheless, col- 
lecting places were also previously chosen randomly. The ideal situation should be the own order to establish the item position.

Ezziane (2000) considered important the use of computational programs in companies to make and maintain them competitive in the market. Currently, several PDC use computational programs to support employees in activities such as organization of CL in the sequence which minimize employees routing. Commonly those programs only provide information when a real order comes to the system, making companies vulnerable for unexpected situations. An effective management may be accomplished only if the company has previously information permitting to visualize and prevent futures problems. It is important a tool capable of making tests and providing information to support decisions.

Computational simulation tools have as one of their main important features the construction of models which represent real systems. Banks et al. (1984) affirm simulation permits to comprehend the whole system and to realize several iterations. This way, the simulation presents itself as one important tool to be explored in a PDC, since it can deal with several variables simultaneously (Marín et al. 1998).

Simulation is classified in continuous and discrete. Taha (1988) and Banks et al. (1984) affirmed that discrete simulation evaluates the system behavior under events occurrences during different period (discretely) while the continuous simulation analyses the behavior during all period (continuously). Normally, continuous simulation uses equations while models of discrete simulation use statistical distribution for variables. This is much simple to manipulate data and, in most cases, represents exactly real systems.

Our goal is to present a discrete simulation model developed in ARENA $^{\circledR} 5.0$ to simulate the items retrieving process of a PDC including several variables related to this task. The goals of this model are to determine the average total time needed by employees to collect parts of an order, permitting to analyze systematically the influences of the following variables to the retrieving time: Quantity of items, number of employees, routing velocity and trolley load capacity; and to establish relationship among pattern flow and random movement with size of companies.

\section{DESCRIPTION OF PDC}

The company, where this research was conducted, is a digging machinery and tractor assembly located in São Paulo State which is responsible for supplying reposition parts. Among several sectors there is one PDC responsible for parts with up to $20 \mathrm{~kg}$ (around 30055 different items). Its dimensions are shown in Figure 1.

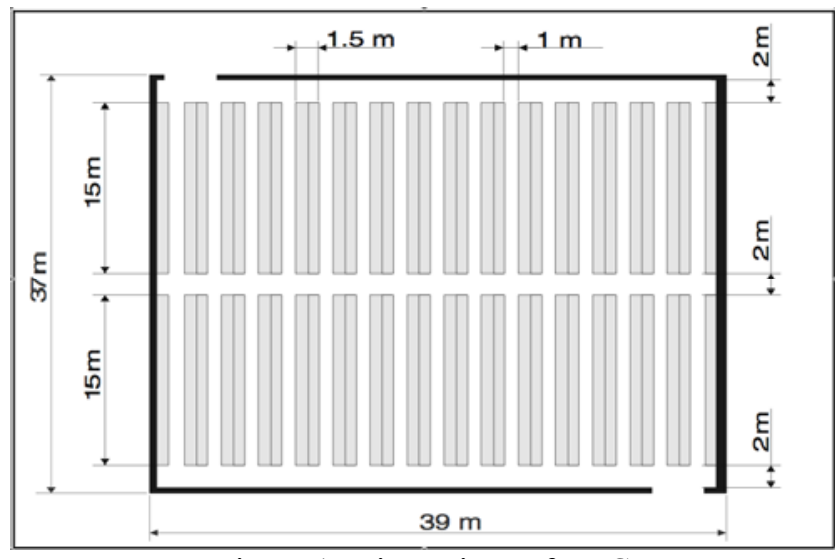

Figure 1: Dimensions of PDC

There is an important area tied to collecting parts activity and that should be considered in modeling. It is the packing area located at the superior left side of Figure 1. Employees leave this area to execute the collecting parts and return to it later. All of 30055 items are distributed in 30 shelves, whose distribution is based on ABC criteria. Table 1 shows the number of items by type.

Table 1: Real distribution of items

\begin{tabular}{|c|l|l|}
\hline Type & \multicolumn{1}{|c|}{ Number of Items } & Percentage \\
\hline A & 1522 & $5.06 \%$ \\
\hline B & 3120 & $10.38 \%$ \\
\hline C & 25413 & $84.56 \%$ \\
\hline Total & 30055 & $100.00 \%$ \\
\hline
\end{tabular}

Reposition of parts to shelves and receiving orders are realized during the morning shift. At the end of this period a list is generated where is registered the requested code and quantity of each item. This list is ordered by code so as to establish the collecting route. In the evening shift (four hours of work) this list is divided in CL and distributed to employees.

There are several manual trolleys in the packing area used by employees in collecting activity. The maximum acceptable load of these trolleys is $120 \mathrm{~kg}$. The route begins in packing area to shelves and when the maximum load is reached, employees return to the same area to unload parts. In the afternoon shift, parts are dispatched to customers.

As illustrated in Figure 1, this PDC is composed by 15 vertical and three horizontal aisles. The name subaisle is given for vertical aisle of each shelf and is $15 \mathrm{~m}$ of long. There are 10 sections (collecting points) in each subaisle. Each section is composed by two subsections, one in left and the other in right side of subaisle. Subsections are divided in drawers for storing parts.

Figure 2 illustrates pattern flow of employees routing in aisles. Numbers close to arrows represent shelves numbers. Group of shelves is named block. 


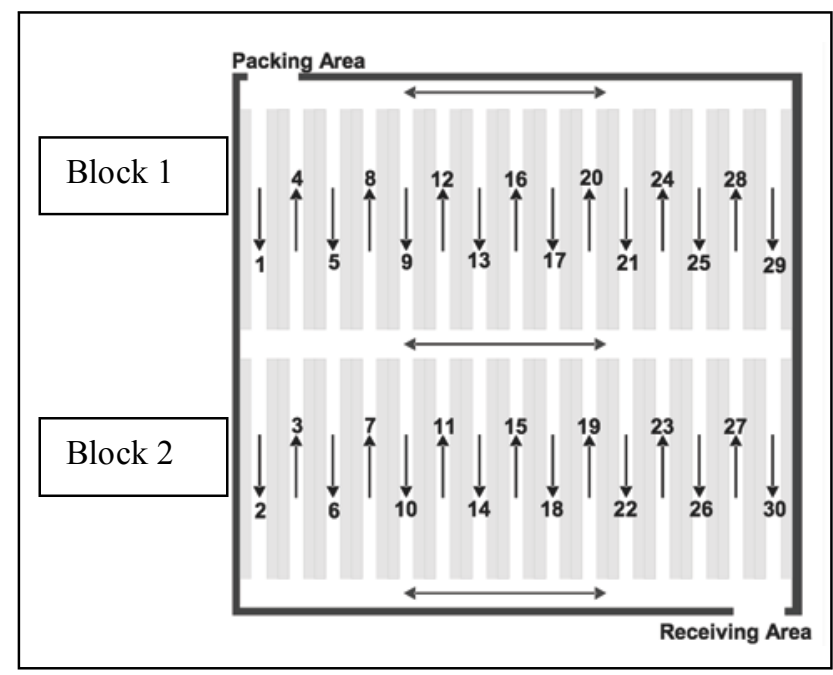

Figure 2: Flow of employees

\section{CHALLENGES}

According to Frazelle (1989), the composition of retrieving time is: identification of local, identification of parts, collection and routing. The colleting time is influenced by the part weight. For routing time, it depends on the routing velocity and distance. Routing velocity depends on transported load and routed distance depends on the localization of each part. For this PDC, there are three types of routes. The first is when employee moves from packing area to first item to be collected (when trolley is empty). The second refers to routing between collected items (same or different shelves). And the last is routing back to the packing area, which occurs after the last item is collected or when trolley capacity is reached.

Flow chart of Figure 3 illustrates steps of modeling. Step generate order creates randomly a list of items which is divided by the number of employees. Next it is calculated the time for the first employee to collect parts of his $\mathrm{CL}$. This process is repeated until the time of last employee is also calculated. All processes are realized in each replication. Steps of calculation of the time spent by each employee consider the time required by the initial routing (from packing area to an item in shelf), the time required to identify the local, to identify part, to collect, to route between items and the time required by final routing (back to packing area). Note that parts weight are constantly verified, because this is the parameter that defines the moment of returning to packing area to unload parts and take another empty trolley to continue the collecting process.

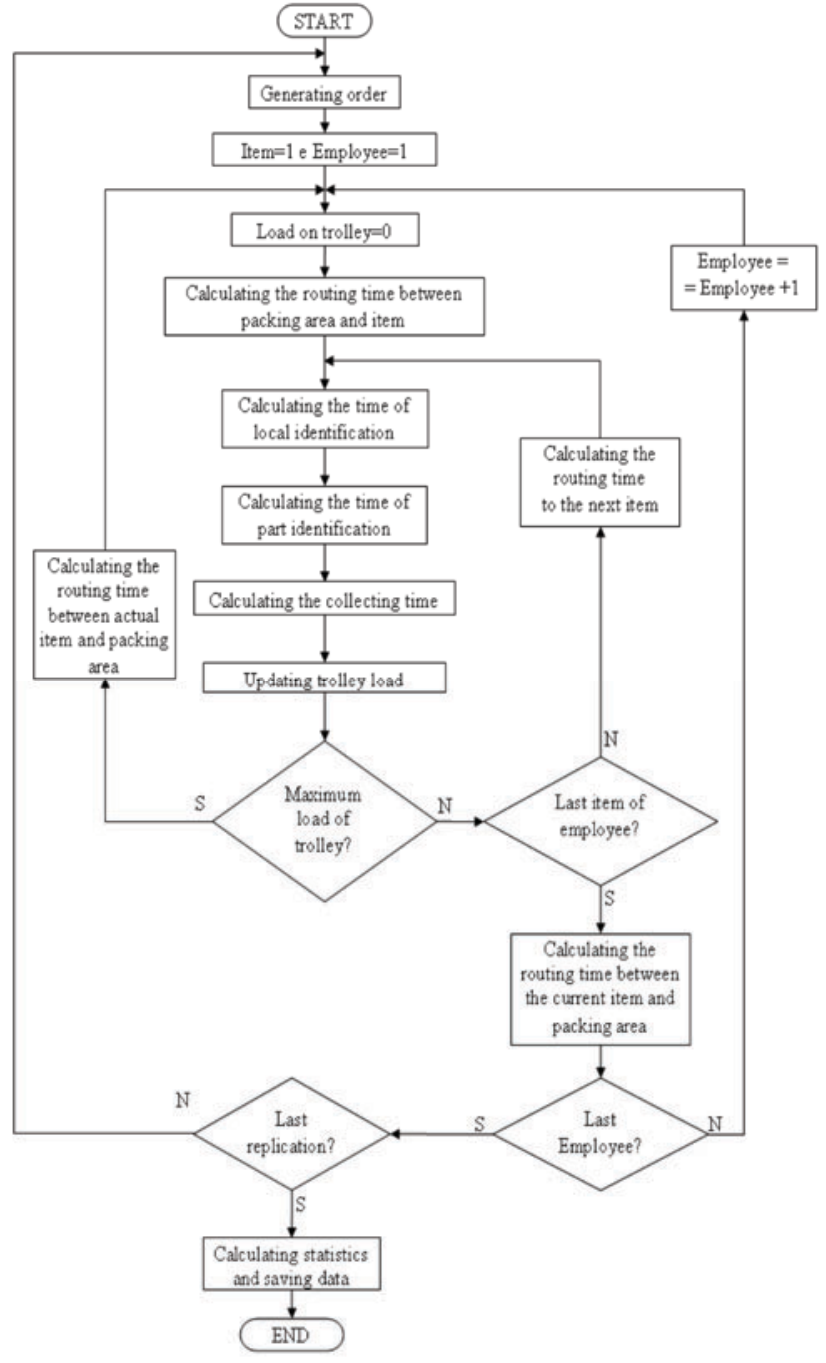

Figure 3: Flow chart of simulation model $(\mathrm{Y}=\mathrm{Yes} ; \mathrm{N}=\mathrm{No})$

In fact, in the real system several employees realize the order picking concurrently but the way of how the simulation model uses to calculate the routing data of each employee is individually and independently.

\section{PDC MODELING IN SIMULATION SOFTWARE ARENA ${ }^{\circledR} 5.0$}

Several variables must be modeled to permit that simulation provides the retrieving process total time closer to the real system, such as shown in following sub-topics: 


\subsection{Items Distribution in Shelves}

The first part of modeling refers to layout of shelves and due to some difficulties to obtain the occupied volume it was assumed a constant density of 1000 items per shelf. Each section stores 100 items.

It is also possible to round the number of items to be stored in the same shelf (Table 2).

Table 2: Rounded quantity of items

\begin{tabular}{|l|r|r|}
\hline Type & Number of Items & \multicolumn{1}{c|}{ Percentage } \\
\hline A & 2000 & $6.67 \%$ \\
\hline B & 4000 & $13.33 \%$ \\
\hline C & 24000 & $80.00 \%$ \\
\hline Total & 30000 & $100.00 \%$ \\
\hline
\end{tabular}

\subsection{Generating Order}

Data of one semester period was analyzed and the number of items per order (NIO) was modeled as triangular distribution with a mean of $1700(1)$.

$\mathrm{NIO}=$ Integer(TriangularDistribution $(1000 ; 1700 ; 1850)$

Data also show that each order has between 30 and $40 \%$ of items type A, 20 to $30 \%$ of items type B and 30 to $50 \%$ of items type C. These data were also modeled such as represented in (2), (3) and (4).

Items A =

Integer (Uniform Distribution $(0.3 ; 0.4) * \mathrm{NIO})$

Items $\mathrm{B}=$

$$
\begin{gathered}
\text { Integer (Uniform Distribution }(0.2 ; 0.3) * \mathrm{NIO}) \\
\text { Items } \mathrm{C}=\mathrm{NIO}-\text { Items A }- \text { Items B }
\end{gathered}
$$

Once those values are defined, the model generates random codes, not repeated codes, for each type of item according to its quantity (for type A codes range from 1 to 2000 , for type B from 2001 to 6000 and type C from 6001 to 30000 ).

To finish order generating step it is necessary to define the parts quantity per item. Uniform distribution is adopted for 1 to $20 \mathrm{~kg}$, but it was inadequate to model for parts "up to $1 \mathrm{~kg}$ " since in real system parts with high weight are less requested than soft parts. So it is used Exponential distribution such as show in Table 3.
Table 3: Definition of parts quantity according to their weights

\begin{tabular}{|l|l|}
\hline Weight of Each Part & \multicolumn{1}{|c|}{ Parts Quantity of Item } \\
\hline Up to $1 \mathrm{~kg}$ & $\begin{array}{l}\text { Integer(Exponential Distribu- } \\
\text { tion(7) })+1\end{array}$ \\
\hline From 1 to $5 \mathrm{~kg}$ & Integer(Uniform Distribution(1;8)) \\
\hline From 5 to $10 \mathrm{~kg}$ & Integer(Uniform Distribution(1;4)) \\
\hline From 10 to $20 \mathrm{~kg}$ & Integer(Uniform Distribution(1;3)) \\
\hline
\end{tabular}

\subsection{Composition of Items Retrieving Process Total Time}

Models of four components of the time are presented in the following.

- Identification of the local: It was modelled by a triangular distribution $(1.5 ; 2.5 ; 4) \mathrm{s}$.

- Identification of part: This time is represented by a triangular distribution $(1 ; 1.5 ; 3) \mathrm{s}$.

- Collection: It is the time required for the employees to move their hands from shelf to trolley with collected part. The triangular distribution used is $(1 ; 3 ; 4)$ s. For Maynard (1970), parts weight can influence on collecting time, called Factor_M. For more detail, see Shih et al. (2005). The collecting time is obtained multiplying time to move hands, Factor_M and quantity of collected parts.

- Routing: The employee's velocity with no load was modeled by a triangular distribution $(0.75 ; 1$; $1.2) \mathrm{m} / \mathrm{s}$. For more detail of load influence on time, Factor_V, see Shih et al. (2005). Routing velocity is obtained multiplying Factor_V by unloaded velocity.

\subsection{Locating Items}

Given code (from 1 to 30000 ) it is possible to calculate the shelf (from 1 to 30 ) and section of subaisle (from 1 to 10 ) where parts are stores using equations (5) and (6).

$$
\begin{gathered}
\text { Shelf }=1+\text { Integer }\left(\frac{(\text { Code }-1)}{1000}\right) \\
\text { Section }=1+\text { Integer }\left(\left(\frac{\text { Code }-1)}{1000}-\operatorname{Integer}\left(\frac{(\text { Code }-1)}{1000}\right)\right) * 10\right)
\end{gathered}
$$

\subsection{Routed Distance}

Due to pattern flow, it is possible to establish equations to routes, such as shown in following sub-topics. 


\subsubsection{Routing from Packing Area to Shelves (When Trolley is Empty)}

This routing is composed by two components. The first depends on destiny shelf and the second depends on section where the item is located. Figure 4 shows an example where item is located in a certain section of shelf 1 .

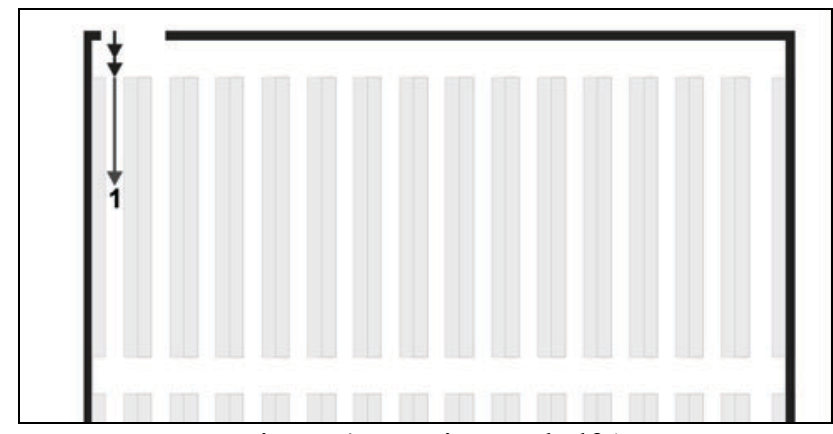

Figure 4: Routing to shelf 1

The first component is presented by two small arrows, where each one represents $1 \mathrm{~m}$ (due to cross-aisle measures, which are 2 meters in width). Second component, named Final Routing (FinRou), is represented by an average arrow and its length can be calculated by equation (7) and its unit is in meters [m]. The value 1.5 of this equation represents dimension of each section.

$$
\text { FinRou }[m]=\text { DestinySection } * 1.5
$$

Generically, routing values in aisles from packing area to aisles sections are shown in Table 4 .

Table 4: Distances from packing area to each section (in meters)

\begin{tabular}{|c|c|c|c|c|c|}
\hline Shelf & Distance & Shelf & Distance & Shelf & Distance \\
\hline 01 & $2.0+$ FinRou & 11 & $48.5+$ FinRou & 21 & $27.0+$ FinRou \\
\hline 02 & $19.0+$ FinRou & 12 & $31.5+$ FinRou & 22 & $44.0+$ FinRou \\
\hline 03 & $38.5+$ FinRou & 13 & $17.0+$ FinRou & 23 & $63.5+$ FinRou \\
\hline 04 & $21.5+$ FinRou & 14 & $34,0+$ FinRou & 24 & $46.5+$ FinRou \\
\hline 05 & $7.0+$ FinRou & 15 & $53.5+$ FinRou & 25 & $32.0+$ FinRou \\
\hline 06 & $24.0+$ FinRou & 16 & $36.5+$ FinRou & 26 & $49.0+$ FinRou \\
\hline 07 & $43.5+$ FinRou & 17 & $22.0+$ FinRou & 27 & $68.5+$ FinRou \\
\hline 08 & $26.5+$ FinRou & 18 & $39.0+$ FinRou & 28 & $51.5+$ FinRou \\
\hline 09 & $12.0+$ FinRou & 19 & $58.5+$ FinRou & 29 & $37.0+$ FinRou \\
\hline 10 & $29.0+$ FinRou & 20 & $41.5+$ FinRou & 30 & $54.0+$ FinRou \\
\hline
\end{tabular}

It is possible to create a calculation procedure which permits to obtain routing value (Figure 5).

\begin{tabular}{|ll|}
\hline $\mathrm{V}(2 ; 19 ; 38.5 ; 21.5)$ & 'Vector composed by four basis values \\
Read PD & "Information of Destiny Shelf \\
Read SD & "Information of Destiny Section \\
$\mathrm{A}=\mathrm{Integer}(\mathrm{PD}-1) / 4)$ & 'Defines the value to be multiplied by 5 \\
$\mathrm{~B}=\mathrm{PD}-4 * \mathrm{~A}$ & 'Defines the value of vector \\
$\mathrm{D}=\mathrm{V}(\mathrm{B})+5 * \mathrm{~A}$ & "Calculates distance $\mathrm{D}$ to destiny shelf \\
$\mathrm{FinRou}=\mathrm{SD} * 1.5$ & "Calculates distance to destiny section \\
$\mathrm{Distance}=\mathrm{D}+$ FinRou & "Calculates total distance
\end{tabular}

Figure 5: Procedure to calculate distances from packing area to section

\subsubsection{Routing from Shelves to Packing Area}

This spent time is also composed by two components of routes. The first component depends on the section and second depends on shelf where section is located. Figure 6 shows an example where the collection is finished in a certain section of shelf 1 .

In Figure 6, the first routing component, named Initial Routing (IniRou), is represented by an average arrow and can be calculated by equation (8).

$$
\operatorname{IniRou}[m]=(10=\text { Section }) * 1.5
$$

Values added to IniRou can be decomposed into four values, as illustrated in Table5.

Figure 7 shows procedure that permits to calculate the routed distance from the last collected part to packing area.

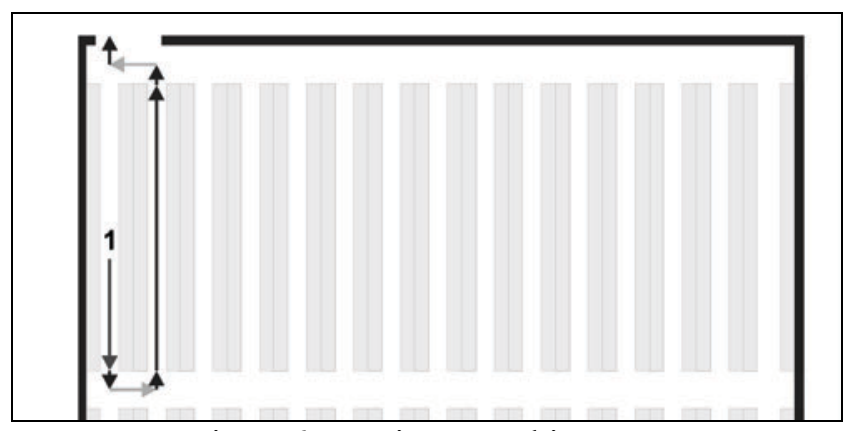

Figure 6: Routing to packing area 


\section{Shih and Júnior}

Table 5: Relationship of distances (in meters)

\begin{tabular}{|c|l|c|c|l|r|}
\hline Shelf & Distance & Relationship & Shelf & Distance & Relationshí \\
\hline $\mathbf{0 1}$ & 24.0 & - & $\mathbf{1 6}$ & 19.5 & $4.5+3 * 5$ \\
\hline $\mathbf{0 2}$ & 41.0 & - & $\mathbf{1 7}$ & 39.0 & $24.0+3 * 5$ \\
\hline $\mathbf{0 3}$ & $\mathbf{2 1 . 5}$ & $21.5+0 * 5$ & $\mathbf{1 8}$ & 56.0 & $41.0+3 * 5$ \\
\hline $\mathbf{0 4}$ & $\mathbf{4 . 5}$ & $4.5+0 * 5$ & $\mathbf{1 9}$ & 41.5 & $21.5+4 * 5$ \\
\hline $\mathbf{0 5}$ & $\mathbf{2 4 . 0}$ & $24.0+0 * 5$ & $\mathbf{2 0}$ & 24.5 & $4.5+4 * 5$ \\
\hline $\mathbf{0 6}$ & $\mathbf{4 1 . 0}$ & $41.0+0 * 5$ & $\mathbf{2 1}$ & 44.0 & $24.0+4 * 5$ \\
\hline $\mathbf{0 7}$ & 26.5 & $21.5+1 * 5$ & $\mathbf{2 2}$ & 61.0 & $41.0+4 * 5$ \\
\hline $\mathbf{0 8}$ & 9.5 & $4.5+1 * 5$ & $\mathbf{2 3}$ & 46.5 & $21.5+5 * 5$ \\
\hline $\mathbf{0 9}$ & 29.0 & $24.0+1 * 5$ & $\mathbf{2 4}$ & 29.5 & $4.5+5 * 5$ \\
\hline $\mathbf{1 0}$ & 46.0 & $41.0+1 * 5$ & $\mathbf{2 5}$ & 49.0 & $24.0+5 * 5$ \\
\hline $\mathbf{1 1}$ & 31.5 & $21.5+2 * 5$ & $\mathbf{2 6}$ & 66.0 & $41.0+5 * 5$ \\
\hline $\mathbf{1 2}$ & 14.5 & $4.5+2 * 5$ & $\mathbf{2 7}$ & 51.5 & $21.5+6 * 5$ \\
\hline $\mathbf{1 3}$ & 34.0 & $24.0+2 * 5$ & $\mathbf{2 8}$ & 34.5 & $4.5+6 * 5$ \\
\hline $\mathbf{1 4}$ & 51.0 & $41.0+2 * 5$ & $\mathbf{2 9}$ & 54.0 & $24.0+6 * 5$ \\
\hline $\mathbf{1 5}$ & 36.5 & $21.5+3 * 5$ & $\mathbf{3 0}$ & 71.0 & $41.0+6 * 5$ \\
\hline
\end{tabular}

\begin{tabular}{|c|c|}
\hline $\begin{array}{l}V(21.5 ; 4.5 ; 24 ; 41) \\
\text { values }\end{array}$ & "Vector composed by four basis \\
\hline Read PQ & 'Information of origin shelf \\
\hline Read SO & 'Information of Origin Section \\
\hline If $P Q=1$ then $D=24$ & 'Definition of value $D$ \\
\hline If $P Q=2$ then $D=41$ & 'Definition of value $D$ \\
\hline \multicolumn{2}{|l|}{ If $P Q>=3$ then } \\
\hline $\begin{array}{l}A=\text { Integer }(\mathrm{PO}-3) / 4) \\
\text { plied by } 5\end{array}$ & 'Defines the value to be multi- \\
\hline $\mathrm{B}=\mathrm{PQ}-2-4 * \mathrm{~A}$ & 'Defines a value of vector \\
\hline $\begin{array}{l}D=V(B)+5 * A \\
D\end{array}$ & "Calculate the value for variable \\
\hline \multicolumn{2}{|l|}{ Enf if } \\
\hline IniRou $=(10-\mathrm{SO}) * 1.5$ & 'Distance to destiny section \\
\hline Distance $=$ IniRou $+\mathrm{D}$ & "Calculates total distance \\
\hline
\end{tabular}

Figure 7: Procedures for calculating distance between a shelf and packing area

\subsubsection{Routing Among Shelves}

There are two situations. First, the next item is located at the same shelf of first item and in this case the distance can be calculated by equation (9).

$$
\text { Dis } \tan c e[m]=(\text { DestinySection }=\text { Section }) * 1.5
$$

Second when the next item is located at other shelf. This situation involves three components: Routings between current item to the end of this same shelf (IniRou), from current shelf to destiny shelf and to destiny section (FinRou).

Routed distances between two shelves depend on definition about which one is origin or destiny shelf. Values showed in two Tables below 6,7 have four common values. However, depending on origin shelf be even or odd, there would be four different values. There are also four common values for routing distance from destiny to shelves 21 to 30, but it are not showed here in Table due to the size issue. Fortunately it is possible to show how to calculate for 21 to 30 which is embedded in the procedure. In summary there are, therefore, 8 basis numbers:

Odd origin shelf: $2 ; 21.5 ; 4.5$ and 24 ;

Even origin shelf: $4.5 ; 21.5 ; 41$ and 24 .

Figure 8 shows a procedure to calculate distance among sections.

Table 6: Routed distances from origin to shelves 1 to 10

\begin{tabular}{|c|c|c|c|c|c|c|c|c|c|c|}
\hline \multirow{2}{*}{\begin{tabular}{c} 
昫 \\
\cline { 2 - 12 }
\end{tabular}} & $\mathbf{0 1}$ & $\mathbf{0 2}$ & $\mathbf{0 3}$ & $\mathbf{0 4}$ & $\mathbf{0 5}$ & $\mathbf{0 6}$ & $\mathbf{0 7}$ & $\mathbf{0 8}$ & $\mathbf{0 9}$ & $\mathbf{1 0}$ \\
\hline $\mathbf{0 1}$ & 0 & 2 & 21.5 & 4.5 & 24 & 7 & 26.5 & 9.5 & 29 & 12 \\
\hline $\mathbf{0 2}$ & - & 0 & 4.5 & 21.5 & 41 & 24 & 9.5 & 26.5 & 46 & 29 \\
\hline $\mathbf{0 3}$ & - & - & 0 & 2 & 21.5 & 4.5 & 24 & 7 & 26.5 & 9.5 \\
\hline $\mathbf{0 4}$ & - & - & - & 0 & 4.5 & 21.5 & 41 & 24 & 9.5 & 26.5 \\
\hline $\mathbf{0 5}$ & - & - & - & - & 0 & 2 & 21.5 & 4.5 & 24 & 7 \\
\hline $\mathbf{0 6}$ & - & - & - & - & - & 0 & 4.5 & 21.5 & 41 & 24 \\
\hline $\mathbf{0 7}$ & - & - & - & - & - & - & 0 & 2 & 21.5 & 4.5 \\
\hline $\mathbf{0 8}$ & - & - & - & - & - & - & - & 0 & 4.5 & 21.5 \\
\hline $\mathbf{0 9}$ & - & - & - & - & - & - & - & - & 0 & 2 \\
\hline $\mathbf{1 0}$ & - & - & - & - & - & - & - & - & - & 0 \\
\hline
\end{tabular}

Table 7: Routed distances from destiny to shelves 11 to 20

\begin{tabular}{|c|c|c|c|c|c|c|c|c|c|c|}
\hline \multirow{2}{*}{ 費 } & \multicolumn{10}{|c|}{ Destiny Shelf } \\
\hline & 11 & 12 & 13 & 14 & 15 & 16 & 17 & 18 & 19 & 20 \\
\hline 01 & 31.5 & 14.5 & 34 & 17 & 36.5 & 19.5 & 39 & 22 & 41.5 & 24.5 \\
\hline 02 & 14.5 & 31.5 & 51 & 34 & 19.5 & 36.5 & 56 & 39 & 24.5 & 41.5 \\
\hline 03 & 29 & 12 & 31.5 & 14.5 & 34 & 17 & 36.5 & 19.5 & 39 & 22 \\
\hline 04 & 46 & 29 & 14.5 & 31.5 & 51 & 34 & 19.5 & 36.5 & 56 & 39 \\
\hline 05 & 26.5 & 9.5 & 29 & 12 & 31.5 & 14.5 & 34 & 17 & 36.5 & 19.5 \\
\hline 06 & 9.5 & 26.5 & 46 & 29 & 14.5 & 31.5 & 51 & 34 & 19.5 & 36.5 \\
\hline 07 & 24 & 7 & 26.5 & 9.5 & 29 & 12 & 31.5 & 14.5 & 34 & 17 \\
\hline 08 & 41 & 24 & 9.5 & 26.5 & 46 & 29 & 14.5 & 31.5 & 51 & 34 \\
\hline 09 & 21.5 & 4.5 & 24 & 7 & 26.5 & 9.5 & 29 & 12 & 31.5 & 14.5 \\
\hline 10 & 4.5 & 21.5 & 41 & 24 & 9.5 & 26.5 & 46 & 29 & 14.5 & 31.5 \\
\hline 11 & 0 & 2 & 21.5 & 4.5 & 24 & 7 & 26.5 & 9.5 & 29 & 12 \\
\hline 12 & - & 0 & 4.5 & 21.5 & 41 & 24 & 9.5 & 26.5 & 46 & 29 \\
\hline 13 & - & - & 0 & 2 & 21.5 & 4.5 & 24 & 7 & 26.5 & 9.5 \\
\hline 14 & - & - & - & 0 & 4.5 & 21.5 & 41 & 24 & 9.5 & 26.5 \\
\hline 15 & - & - & - & - & 0 & 2 & 21.5 & 4.5 & 24 & 7 \\
\hline 16 & - & - & - & - & - & 0 & 4.5 & 21.5 & 41 & 24 \\
\hline 17 & - & - & - & - & - & - & 0 & 2 & 21.5 & 4.5 \\
\hline 18 & - & - & - & - & - & - & - & 0 & 4.5 & 21.5 \\
\hline 19 & - & - & - & - & - & - & - & - & 0 & 2 \\
\hline 20 & - & - & - & - & - & - & - & - & - & 0 \\
\hline
\end{tabular}




\section{Shih and Júnior}

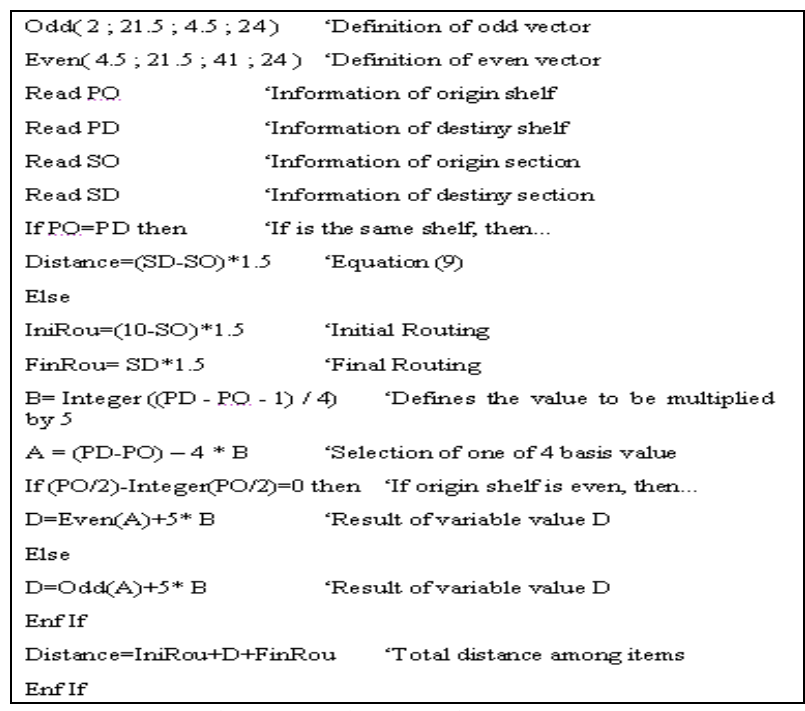

Figure 8: Procedure to calculate distance among sections

\section{EXPERIMENTS}

\subsection{Example 1 - Reasons for the Differences of Travel Times}

Figure 9 presents a bar chart constructed by average values of four components of total time with five employees and for 30 replications. Average number of items per order was 1478 , three of the components were almost the same (identification of the local, part and collection).

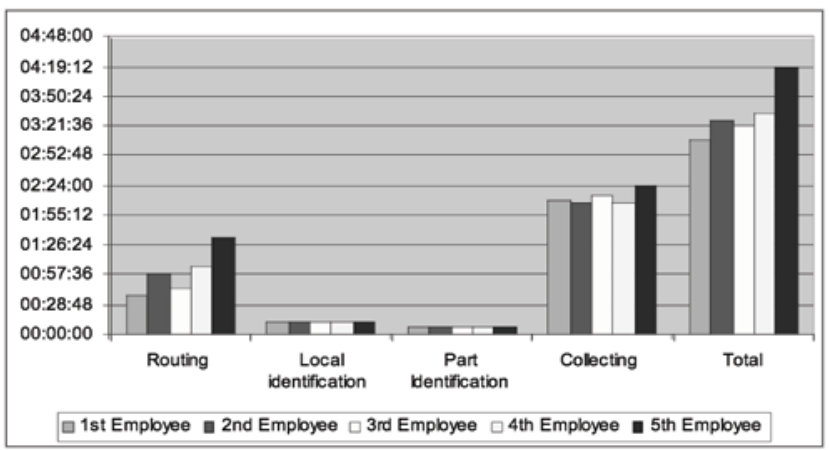

Figure 9: Composition of total time for five employees (in Hours)

Note that $5^{\text {th }}$ employee takes more than four hours to complete his task, over than evening shift. Graph shows that differences are in routing times. This is because $1^{\text {st }} \mathrm{em}-$ ployee collects only parts located close to packing area while $5^{\text {th }}$ employee collects parts of last shelves. Let us consider one replication, for instance:

For this replication, this order is 1417 items with 476 codes type A, 316 type B and 625 type C, see Table 11 . Employees $1^{\text {st }}$ to $4^{\text {th }}$ have to collect 282 items while $5^{\text {th }}$ employee, 284. "Item" column of this Table shows the first and last number of items of CL while "Code" column shows correspondent part code. Note that $5^{\text {th }}$ employee takes more than four hours to complete his task, over than evening shift.

Data of Table 8 show the $1^{\text {st }}$ employee works only in shelves 1 and 2 while $5^{\text {th }}$ employee works in shelves 18 to 30 . It can be concluded that distance among collected items type $\mathrm{C}$ is higher than distance between items $\mathrm{A}$ and $\mathrm{B}$.

Table 8: Average for 30 replications

\begin{tabular}{|c|c|c|c|c|c|c|}
\hline Employee & Total Time & $\begin{array}{c}\text { Routed } \\
\text { Distance }\end{array}$ & Ite m & Code & Type & Shelf \\
\hline \multirow{2}{*}{1} & \multirow{2}{*}{$3 \mathrm{~h} 8 \mathrm{~min} 46 \mathrm{~s}$} & \multirow{2}{*}{$1750.00 \mathrm{~m}$} & 1 & 3 & A & 1 \\
\hline & & & 283 & 1148 & A & 2 \\
\hline \multirow{2}{*}{2} & \multirow{2}{*}{$3 \mathrm{~h} 27 \min 45 \mathrm{~s}$} & \multirow{2}{*}{$2822.50 \mathrm{~m}$} & 284 & 1152 & A & 2 \\
\hline & & & 566 & 2503 & B & 3 \\
\hline \multirow{2}{*}{3} & \multirow{2}{*}{$3 \mathrm{~h} 21 \mathrm{~min} 54 \mathrm{~s}$} & \multirow{2}{*}{$2371.00 \mathrm{~m}$} & 567 & 2504 & B & 3 \\
\hline & & & 849 & 6018 & $\mathrm{C}$ & 7 \\
\hline \multirow{2}{*}{4} & \multirow{2}{*}{$3 \mathrm{~h} 34 \mathrm{~min} 9 \mathrm{~s}$} & \multirow{2}{*}{$3279.00 \mathrm{~m}$} & 850 & 6122 & $\mathrm{C}$ & 7 \\
\hline & & & 1132 & 18059 & $\mathrm{C}$ & 18 \\
\hline \multirow{2}{*}{5} & \multirow{2}{*}{ 4h18min $57 \mathrm{~s}$} & \multirow{2}{*}{$4746.50 \mathrm{~m}$} & 1133 & 18060 & $\mathrm{C}$ & 18 \\
\hline & & & 1417 & 29871 & $\mathrm{C}$ & 30 \\
\hline
\end{tabular}

\subsection{Example 2}

Let us consider an unexpected situation. Suddenly in a certain day of the week one employee is sick and he is not available to work. Is it capable for the remaining four employees to collect parts in a period of 4 hours? If it is not, what can be done with other variables to fill this gap? Figure 10 shows results of each component of the retrieving time and note that total time really is higher for most employees. What can be done in a short term just to supply the necessity of one absent employee to complete collecting in a period of four hours? Let us now suppose that routing velocity of employees is increased to $1,5 \mathrm{~m} / \mathrm{s}$, it yields the following results as shown in Figure 11.

Just with this policy, the company can reduce the retrieving time to four hours filling one employee's gap. Other variables can also be altered, such as shown in example 3 .

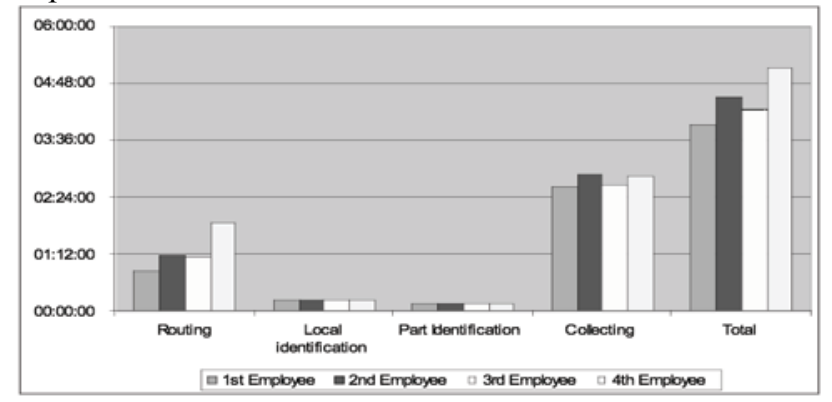

Figure 10: Composition of total time for five employees (in Hours) 


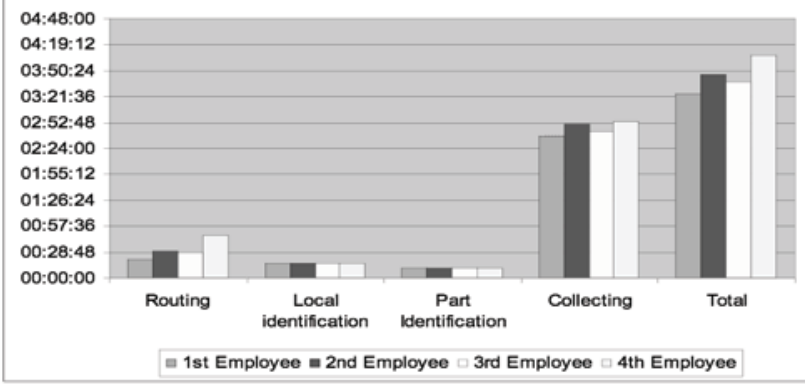

Figure 11: Total time when one employee is out (velocity of $1.5 \mathrm{~m} / \mathrm{s}$ )

\subsection{Example 3}

Let us consider another unexpected situation. Due to some broken machines in the packing area, all of 5 men are allocated simultaneously there to accomplish customer requirements, because it becomes more urgent than collecting parts (customer satisfaction issue), and consider also women are used in retrieving process instead of men. Due to their physical endurance, they can not push trolleys with $120 \mathrm{~kg}$ of load only $100 \mathrm{~kg}$ or less. How many women would be necessary to finish this process in a period of four hours with $100 \mathrm{~kg}$ of load on trolley, for example? Figure 12 shows results under those conditions. Increasing the number of employees from 5 to 6 it is possible to accomplish their tasks with load of $100 \mathrm{~kg}$.

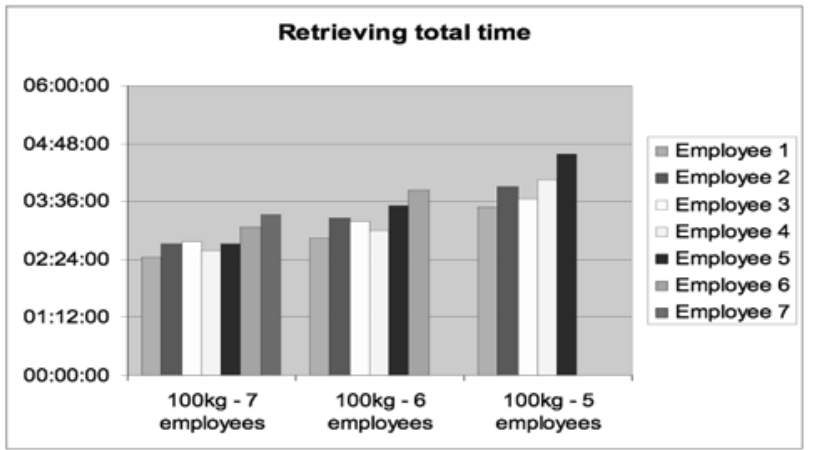

Figure 12: For $100 \mathrm{~kg}$ of load on trolley : employees $\mathrm{x}$ total time

\section{CONCLUSIONS}

The goal of this paper was to present a model of a PDC aiming at determining the average total time spent by employees to collect parts of one order. Several procedures were shown to model variables that affect this time making results closer to the reality.

Although the presented model was developed for a specific PDC, it can be used to simulate different number of items, sections, shelves (only for 3 cross-aisles). This modification can be done altering equations 5, 6, 7, 8 and 9 and also three presented procedures.
Simulation has an important task in manufacturing systems providing information previously without changing real system. Simulation is not applied to obtain solutions, but provide information to support managers in decisions. For instance, it is possible to estimate the required number of employees that permits order consolidation in a established period of time avoiding delivering delay.

From data presented in Table 8, for instance, it is possible to conclude that dividing equally order in a similar parts (CL) will result in an unbalanced spent time for collecting consolidation. This time may become higher than 4 hours of evening shift. It is possible to search for a method that permits balancing average total time by each employee. A linear unbalancing of CL is presented by Shih et al. (2004b) to balance the time spent by each employee. New methods can also be proposed for future searches related to dividing CL.

\section{ACKNOWLEDGMENTS}

We gratefully acknowledge Brazilian financial support Capes and CNPq.

\section{REFERENCES}

Banks, J., J. S. Carlson, and B. L. Nelson. 1984. DiscreteEvent System Simulation. 2th ed. New Jersey: Prentice-Hall.

Caron, F., G. Marchet, and A. Perego. 1998. Routing policies and COI-based storage policies in picker-to part systems. International Journal of Production Research 36(3): 713-732.

Caron, F., G. Marchet, and A. Perego. 2000. Layout in manual picking systems: a simulation approach. Integrated Manufacturing Systems 11(2): 94-104.

Coyle, J. J., E. J. Bardi and E. J. Langley. (1996). The Management of Business Logistics. 6th ed. Saint Paul: West publishing.

Ezziane, Z. 2000. Evaluating customer service performance in warehousing environments. Logistics Information Management 13(2): 90-94.

Frazelle, E. H. 1989. Stock Location Assignment and Order Picking Productivity, $\mathrm{PhD}$ Thesis.

Goetschalckx, M., and H. D. Ratliff. 1988. Order picking in an aisle. IIE Transactions 20(1): 53-62.

Hall, R. W. 1993. Distance approximations for routing manual pickers in a warehouse. IIE Transactions 25(4).

Jarvis, J. M., and E. D. McDowell. 1991. Optimal product layout in an order picking warehouse. IIE Transactions 23: 93-102.

Junior, N. S. 2000. It's in the pick: the right picking process can contribute to a company's ability to embrace ecommerce. IIE Solutions. 
Kallina, C., J. Lynn. 1976. Application of the cube-perorder index rule for stock location in a distribution warehouse. Interfaces 7(1).

Makris, P. A., and L. G. Giakoumakis. 2003. Kinterchange heuristic as an optimization procedure for material handling applications. Applied Mathematical Modelling 27: 345-358.

Marín, R. M., J. Garrido, J. L. Trillo, J. Sáez, and J. Armesto. 1998. Design and simulation of an industrial automated overhead warehouse. Integrated Manufacturing Systems 9(5): 308-313.

Maynard, H. B. 1970. Manual de Engenharia de Produção: Padrões de Tempos Elementares PréDeterminados, São Paulo: Edgard Blücher.

Ratliff, H. D., and A. S. Rosenthal. 1983. Order-picking in a rectangular warehouse: a solvable case of traveling salesman problem. Operations Research 31(3): 507521.

Rana, K. 1990. Order picking in narrow-aisle warehouses. International Journal of Physical Distribution and Logistics Management 20(2).

Shih, Y. C., M. C. Yamada, and A. J. V. Porto. 2004a. Análise do impacto das atividades críticas na eficiência e efetividade dos sistemas de armazenamento utilizando planejamento de experimentos. In: Proceeding of the 2004 SAE-Brazil Santo Amaro, São Paulo.

Shih, Y. C., J. H. C. G. Júnior, S. Nonato, and A. J. V. Porto. 2004b. Unbalacing the items of the collecting list to reduce the retrieving total time. Journal Produto \&Produção 7(2): 27-38.

Slack, N., S. Chambers, C. Harland, A. Harrisson, and R. Jonhston. 1999. Administração da Produção. São Paulo: Atlas.

Taha, H. A. 1988. Simulation Modeling and Simnet, New Jersey: Prentice Hall.

Van Den Berg, J. P. 1996. Planning and Control of Ware housing Systems. Ph.D. Thesis, University of Twente, Fac. Mech. Engrg., Enschede, The Netherlands.

\section{AUTHOR BIOGRAPHIES}

SHIH Y. CHIN is a Doctoral degree student by the Mechanical Engineering of São Carlos (USP) - Brazil. He received his MSc. in 2005. His researches are focused on modeling, optimization, improvement and scenario evaluation of manufacturing systems. He is graduated in Production Engineering in 2002 at the same College. His e-mail address is <syschineyahoo.com>.

JOSÉ H. C. G. JÚNIOR is Assistant Professor of Department of Mechanical Engineering at the University of Itajubá, Brazil. He received his $\mathrm{PhD}$ degree in Mechanical Engineering in 1990. His researches are focused on design, modeling, optimization, improvement and evaluation of discrete event systems, mainly the manufacturing systems.

\author{
His e-mail address
}

is 